\title{
Antibiotics, the Life Saving Medicine
}

\author{
Benjamin Lu
}

Department of Molecular and Cellular Biology, University of Guelph, Guelph, Ontario, Canada

Received: March 23, 2018; Accepted: April 27, 2018 ; Published: May 5, 2018

*Corresponding author: Benjamin Lu, Department of Molecular and Cellular Biology, University of Guelph, Guelph, Ontario, Canada, Tel: +1-5198244120; Fax: +1-519-8372075; Email: blu@uoguelph.ca

\begin{abstract}
Doctors do not always understand the biochemistry of antibiotics and, they make wrong choices of antibiotics that cause harms to their patients. This article is written with the hope that doctors and patients be better educated about antibiotics, and that antibiotics are truly the life-saving medicine.
\end{abstract}

\section{Introduction}

On July 7, 1937, the Japanese military invaded China that started the Second World War. The daily air raid by Japanese planes in my home-town, Chang Zhou, made it impossible for schools to function, and to protect students from harms, my father's school, Talmage College, moved to a northern village in the province of Fujien, China, named Hua-an. There were no doctors in the area, and so, when we got sick, there were only some forms of home remedies. I remembered I suffered a sore throat, my grandmother told me to eat rotten oranges covered with a blue mold. I did that and, I was cured. In those days, people knew it worked but did not know why. I now know why, because the blue mold is a fungus, named Penicillium notatum which is the source for the antibiotics Penicilline as discovered by Sir Alexander Fleming in 1928. The first antibiotic discovered, before Penicilline at the end of World-War II, was named sulfadiazine, and it worked wonders until it was found to have toxic side-effect, and, abandoned. After Penicilline, many different types of antibiotics were found, and, the choice of use by doctors has become an issue. In many cases, wrong prescription may be harmful to patients and even death.

\section{Observations and Discussion}

When I learned from the National news cast that nine -people died of Streptococcus infections, I asked myself this question: "Why were they not given proper antibiotics? As strep throat should be treatable by proper selection of antibiotics. Was it possible that their doctors gave them the antibiotics that did not work?" These questions prompted me to want to share some of my personal experience dealing with wrong prescriptions of antibiotics by doctors. The following are two case reports.

\section{Case 1:}

When my six-year old son had a hot-dog day in school, he contracted a rare disease, which his pediatrician claimed that he had not encountered in his practice, my son was hospitalized. After several weeks in the hospital, my son was not recovering. I asked the nurse, who was taking care of him, why his pediatrician did not give him antibiotics for his infection. I was told that he was on antibiotics from day one. "Which antibiotics was he given?" I asked. She replied that he was given Erythromycin. Out of curiosity, I went home and checked on the book I have on my book-shelf, entitled: ANTIBIOTICS, a critical review, edited by W. Kurylowicz, by POLISH MEDICAL PUBLISHERS,

warsaw, 1976 [1]. The statement about Erythromycin is as follow: "This antibiotic is fairly-well distributed in the organs and tissues, but it penetrates poorly into the cells." If Erythromycin cannot enter the bacterial cells, no wonder why my son was not recovering. With that information, I then requested my good family doctor to prescribe TETRACYCLINE for my son. (Dr. R said to me, "you are a professor of Molecular Biology, I trust your suggestion.") With Tetracycline, my son recovered in three days, and he came home well.

That Erythromycin penetrates poorly into the cells may be explained by its molecular mass, which is $733.94 \mathrm{~g}$ mol- 1 . Which is too big to penetrate the cell membrane by diffusion. Thus, if it is unable to enter the cells, then it cannot have the antibacterial activities for patients suffering from diseases such as Strep throat or pneumonia. That Erythromycin is ineffective is clearly demonstrated in a photograph published by Charles R. Woods, MD, MS, 2009 [2].

In another case, I was prescribed the antibiotic, Azithromycin, when I protested; I was told that this is new and improved! Azithromycin is a derivative product of Erythromycin, and therefore not an effective antibiotic. Unfortunately, Erythromycin and Azithromycin are frequently prescribed by doctors.

\section{Case No. 2:}

Last September, I suffered a shoulder injury doing the yardwork; I visited Physiotherapy-clinics for treatments. During one of the treatment-sessions, I contracted a strep-throat infection, which turned into pneumonia quickly. I visited my new family doctor (Dr. G) who gave me an antibiotic, named: Auro-Moxiflaxacin 400 $\mathrm{mg}$, I took it for five days, and there was no improvement. I sensed that this antibiotic is not working, and I thought I was going to die 
as did my mother. Fortunately, I met a Nurse-practitioner, and I asked her for help, to give me Doxycycline. She asked me to take an X-ray to show that I had bacteria in my lung. I did, and she gave me Doxycycline as I requested. After three days with Doxycycline, I already felt better, and I continued with the medication until I finished the ten days prescription. I was completely recovered. Unfortunately, I suffered from another round of throat infection. I visited Doctor G as soon as I could. “Did Doxycycline work?" Dr. G asked, "Yes, it did." I replied. So, he gave me another ten days prescription of Doxycycline. Dr. G also gave me an instruction: "If you feel better, then take an X-ray in thirty days." This was to show that no more bacteria in my lung.

Auro-Moxiflaxacin is an antibiotic that inhibits DNA replication. So, the bacteria in my lung cannot replicate, but the bacteria, already in my lung, continued to produce toxic substance into my body. This was why my pneumonia continued to worsen. In contrast, Doxycycline inhibits protein synthesis. So, the disease symptom is relieved and, the bacteria are killed. I was lucky that I met the Nurse Practitioner who was a life saver.

\section{References}

1. W Kurylowicz (contributors: W. Kurylowicz, W. Chojnowski, K. Raczynska-Bojanowska, Z.Kowszyk-Gindifer.Poliih), ANTIBIOTICS, A critical review, Polish Medical Publishers, Warsaw. Distributed by American Society for Microbiology. 1976; p.204.

2. Charles R Woods. Macrolide-Inducible Resistance to Clindamycin and the D-Test. The Pediatric Infectious Disease Journal. 2009;28(12):11151118. 